\section{AB0910 LONG-TERM GOLIMUMAB RETENTION RATE IN PATIENTS WITH PSORIATIC ARTHRITIS. IS CONCOMITANT DMARD IMPORTANT?}

B. Serrano-Benavente ${ }^{1,2}$, C.M. González-Fernández ${ }^{1,2}$, L. Valor ${ }^{1}$, I. Janta ${ }^{1}$, R. D. González-Benítez ${ }^{1}$, C. Sáenz Tenorio ${ }^{1}$, J.C. Nieto-González ${ }^{1}$, J.G. OvallesBonilla ${ }^{1}$, J. Martínez-Barrio ${ }^{1}$, M. Correyero Plaza ${ }^{1}$, L. García-Montoya ${ }^{1}$, F.J. LópezLongo ${ }^{1,2}$, I. Monteagudo Saez ${ }^{1}{ }^{1}$ Rheumatology, Hospital General Universitario Gregorio Marañón; ${ }^{2}$ Faculty of Medicine, Universidad Complutense de Madrid, Madrid, Spain

Background: The efficacy of Golimumab treatment in psoriatic arthritis (PsA) patients has been widely documented.

Objectives: The aim of this study was to analyse the long-term retention rate of golimumab and to identify independent predictors of drug retention in patients with PsA including concomitant synthetic disease-modifying antirheumatic drugs (sDMARD)

Methods: Prospective monocentric cohort of PsA patients treated with golimumab according to clinical practice. Study was approved by local Ethics Committee. Demographic and clinical variables were analysed with Cox proportional hazard regression model.

Results: 48 patients were included, 20/48 (41.7\%) oligoarticular, 19/48 (39.6\%) polyarticular and $9 / 48(18.7 \%)$ with peripheral and axial PsA. The baseline characteristics of the patients are shown in table 1.

Abstract AB0910 - Table 1. Baseline demographic and clinical characteristics of the patients.

\begin{tabular}{lc}
\hline Age -mean (SD)-years & $48.3(11.1)$ \\
\hline Female gender (\%) & $25(52.1 \%)$ \\
Mean evolution time- (SD)- years & $8.4(7.9)$ \\
TJC - mean (SD) & $4.1(4.1)$ \\
SJC - mean (SD) & $2.9(2.7)$ \\
CRP mg/dl - mean (SD) & $0.6(0.7)$ \\
DAS 28- CRP - mean (SD) & $3.7(1.5)$ \\
Concomitant DMARD (\%) & $24(50 \%)$ \\
Biological Therapy naïve (\%) & $25(52.1 \%)$ \\
\hline
\end{tabular}

Follow-up time was 89.25 patients-year. Mean survival time was 40.3 months (95\% Cl: 32.0-48.5). Age, mean evolution time and previous biological use were significant in the univariate analysis. Concomitant SDMARD had no influence on golimumab retention rate (HR: $1.3 ; 95 \% \mathrm{Cl}$ : 0.5-3.2; p: 0.6). Figure 1. When golimumab was used as first or second biologic treatment, it had a better retention rate than when it was used as third or fourth, but did not reach statistical significance (HR: 2.3 ; IC 95\%: 0.8-6.2; $p=0.1)$. 18/48 patients $(37.5 \%)$ withdrew golimumab treatment. $13 / 18(72.2 \%)$ due to lack of efficacy, $1 / 18(0.6 \%)$ due to adverse events and $4 / 18(22.2 \%)$ due to other reasons.

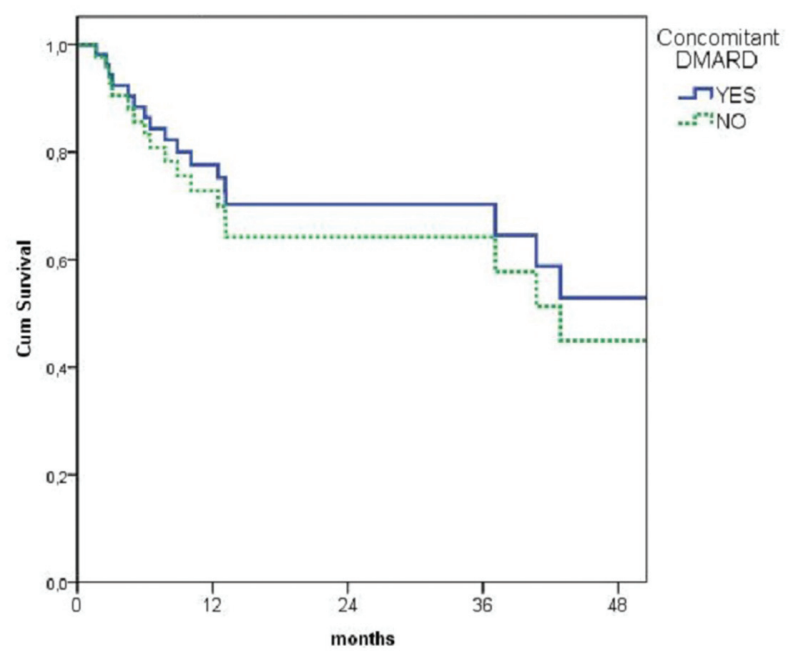

Abstract AB0910 - Figure 1. Golimumab retention rate and concomitant DMARD

Conclusions: Real-world Golimumab retention rate in patients with PsA was good and did not depend on concomitant treatment with sDMARD. When used as first or second biologic, Golimumab retention rate tended to be better.

Disclosure of Interest: None declared

DOI: 10.1136/annrheumdis-2018-eular.4111

\section{$\mathrm{AB} 0911$ \\ THE RELATIONSHIP BETWEEN NEUROPATHIC PAIN AND DISEASE ACTIVITY, SLEEP, FATIGUE, QUALITY OF LIFE IN PATIENTS WITH PSORIATIC ARTHRITIS}

C. Unal ${ }^{1}$, F. Ulutatar ${ }^{1}$, M.T. Duruoz ${ }^{2} .{ }^{1} P M R$ Department, ${ }^{2} P M R$ Department, Rheumatology Division, Marmara University School of Medicine, Istanbul, Turkey

Background: Neuropathic pain (NP) is composed of several abnormal sensations, including burning, prickling hyperalgesia and allodynia. NP is a common problem in rheumatic diseases such as rheumatoid arthritis and ankylosing spondylitis due to inflammatory processes. Previous studies showed that NP in other rheumatic diseases had a negative influence on sleep and quality of life. ${ }^{1,2}$

Objectives: To examine the relation of neuropathic pain symptoms in Psoriatic Arthritis (PsA) with demographic, clinical and functional parameters.

Methods: PsA patients according to CASPAR criteria were recruited into the study. Demographic and clinical parameters were noted. PainDETECT measurement tool was used for evaluation of NP. Physical examination such as manual muscle testing and sensory examination for hyperalgesia and allodynia was performed (pinprick and light touch test). Disease Activity Score-28 (DAS-28) was noted for disease activity. Associations of NP with quality of life, sleep and fatigue were analysed by filling out Psoriatic Quality of Life (PsAQoL), Pittsburgh Sleep Quality Index (PSQI), Multidimensional Assessment of Fatigue (MAF). PainDETECT scores were categorised as no NP ( $<12$ points), ambiguous NP (13-18 points), probable NP ( $\geq 19$ points). Group analysis was performed with Independent-Samples Kruskal-Wallis test. Spearman correlation coefficient (rho) was used for correlations between functional parameters. $p<0.05$ was accepted as significant.

Results: Forty eight PsA patients (31 female, 17 male) with a mean age 50.4 years (SD:10.0) and mean disease duration 92.2 months (SD: 90.2) were recruited into the study. The number of patients with ambiguous NP was 6 patients (4 female, 2 male) and probable NP was 12 patients ( 10 female, 2 male). The mean scores of PSQI, PSAQoL and MAF were significantly higher in patients with NP $(p<0.05)$. There was no difference in mean scores of DAS-28 and disease duration among groups. The correlations between PainDETECT and other func tional parameters were found moderate-strong as PSQI (rho=0.43, $p=0.002$ ), MAF (rho=0.44, $p=0.002$ ), PsAQoL ( $r h o=0.66, p=0.0005$ ). Also, the probability of $\mathrm{NP}$ existence increased with the age ( $\mathrm{rho}=0.40, \mathrm{p}=0.01$ ). There was no significant correlation between and clinical parameters such as disease duration and DAS 28 ( $p>0.05)$.

Conclusions: These findings suggest that a substantial number of PsA patients suffering from NP. The neuropathic pain symptoms are found to be associated with worse self-reported quality of life and sleep disturbances. It is important to consider the existence of NP in the assessment and treatment process of PSA.

\section{REFERENCES}

[1] O'Connor AB, et al. Neuropathic pain: quality-of-life impact, costs and cost effectiveness of therapy. Pharmacoeconomics. 2009; 27:95-112.

[2] Argoff CE, et al. The coexistence of neuropathic pain, sleep, and psychiatric disorders: a novel treatment approach. Clin J Pain. 2007; 23:15-22.

Disclosure of Interest: None declared

DOI: 10.1136/annrheumdis-2018-eular.6766

\section{AB0912 TWO-YEAR EFFICACY AND SAFETY OF GUSELKUMAB FOR TREATMENT OF MODERATE-TO-SEVERE} PSORIASIS: PHASE 3 VOYAGE 1 TRIAL

C.E. Griffiths ${ }^{1}$, K.A. Papp ${ }^{2}$, A.B. Kimball ${ }^{3}$, B. Randazzo ${ }^{4}$, Y. Wasfi ${ }^{4}$, S. Li $i^{4}$, Y.K. Shen ${ }^{4}$, A. Blauvelt ${ }^{5} .{ }^{1} U$ of Manchester, Manchester, UK; ${ }^{2}$ K. Papp Clinical Research and Probity Research Inc, Waterloo, Canada: ${ }^{3}$ Harvard Medical Faculty Physicians at Beth Israel Deaconess Medical Center, Inc, Boston; ${ }^{4}$ Janssen Research and Development, LLC, Spring House; ${ }^{5}$ Oregon Medical Research Center, Portland, USA

Background: Guselkumab (GUS) is an interleukin-23 inhibitor recently approved in the US for treatment of moderate-to-severe psoriasis.

Objectives: Efficacy and safety data for up to 100 wks of GUS treatment are reported.

Methods: In the VOYAGE 1 Phase 3, randomised, double-blind, placebo/active comparator-controlled trial, 837 patients were randomised at baseline to placebo (PBO) at wks0/4/12 then GUS $100 \mathrm{mg}$ at wks16/20 and $\mathrm{q} 8 \mathrm{w}$ ( $\mathrm{n}=174)$; GUS at wks0/4/12, and q8w ( $n=329)$; or adalimumab (ADA) $80 \mathrm{mg}$ at wk $0,40 \mathrm{mg}$ at wk1, and q2w through wk47 then GUS at wk52 and q8w $(n=334)$. Efficacy was assessed using nonresponder imputation through wk48 and treatment failure rules from wks52-100.

Results: Among patients randomised to GUS, or PBO $\rightarrow$ GUS at wk16, efficacy (PASI, Psoriasis Area and Severity Index; IGA, Investigator's Global Assessment) was maintained from wks52-100 with continuous GUS treatment. Among those 
randomised to ADA ( $\rightarrow$ GUS at wk52), efficacy improved from wks52-100. Similar findings were observed for patient-reported outcomes (PSSD, Psoriasis Symptoms and Signs Diary; DLQI, Dermatology Life Quality Index; table 1). Through wk100, there were no disproportionate increases in rates of Adverse Events (AEs) compared with rates through wk48. Serious $A E$ rates were low and remained stable; no TB, opportunistic infections, or serious hypersensitivity reactions were reported.

Abstract AB0912 - Table 1. Efficacy assessments in VOYAGE 1 (wks48/52-100); n\%

\begin{tabular}{lcccccc}
\hline & \multicolumn{2}{c}{ PBO $\rightarrow$ GUS } & \multicolumn{2}{c}{ GUS } & \multicolumn{2}{c}{ ADA $\rightarrow$ GUS } \\
\hline & wk52 & wk100 & wk52 & wk100 & wk52 & wk100 \\
\hline $\mathbf{n}$ & 161 & 158 & 307 & 290 & 279 & 275 \\
PASI90 & 127 & 130 & 246 & 238 & 141 & $223(81.1)$ \\
& $(78.9)$ & $(82.3)$ & $(80.1)$ & $(82.1)$ & $(50.5)$ & \\
PASI100 & $75(46.6)$ & $87(55.1)$ & 155 & 142 & $67(24.0)$ & $142(51.6)$ \\
& & & $(50.5)$ & $(49.0)$ & & \\
Mean\%PASI & 94.6 & 95.5 & 92.3 & 93.1 & 77.6 & $94.2(12.6)$ \\
improvement(SD) & $(9.1)$ & $(7.8)$ & $(17.3)$ & $(16.6)$ & $(31.9)$ & \\
IGA0/1 & 142 & 134 & 254 & 239 & 168 & $231(84.0)$ \\
& $(88.2)$ & $(84.8)$ & $(82.7)$ & $(82.4)$ & $(60.4)$ & \\
IGA0 & $86(53.4)$ & $93(58.9)$ & 165 & 156 & $76(27.3)$ & $153(55.6)$
\end{tabular}

(53.7) (53.8)

\begin{tabular}{|c|c|c|c|c|c|c|}
\hline & wk48 & wk100 & wk48 & wk100 & $\begin{array}{l}\text { ADA } \\
\text { wk48 }\end{array}$ & $\begin{array}{c}\text { ADA } \rightarrow \text { GUS } \\
\text { wk100 }\end{array}$ \\
\hline $\begin{array}{l}\text { PSSD symptom } \\
\text { score }=0^{\mathrm{ab}}\end{array}$ & $\begin{array}{c}46 / 129 \\
(35.7)\end{array}$ & $\begin{array}{c}49 / 118 \\
(41.5)\end{array}$ & $\begin{array}{c}104 / 248 \\
(41.9)\end{array}$ & $\begin{array}{c}89 / 225 \\
(39.6)\end{array}$ & $\begin{array}{c}63 / 273 \\
(23.1)\end{array}$ & $\begin{array}{c}94 / 225 \\
(41.8)\end{array}$ \\
\hline $\begin{array}{l}\text { PSSD sign } \\
\text { score }=0^{\text {ab }}\end{array}$ & $\begin{array}{c}37 / 129 \\
(28.7)\end{array}$ & $\begin{array}{c}44 / 118 \\
(37.3)\end{array}$ & $\begin{array}{c}89 / 248 \\
(35.9)\end{array}$ & $\begin{array}{c}69 / 225 \\
(30.7)\end{array}$ & $\begin{array}{l}51 / 274 \\
(18.6)\end{array}$ & $\begin{array}{c}66 / 226 \\
(29.2)\end{array}$ \\
\hline DLQI0/1 ${ }^{\mathrm{ac}}$ & $\begin{array}{c}111 / 159 \\
(69.8)\end{array}$ & $\begin{array}{c}126 / 152 \\
(82.9)\end{array}$ & $\begin{array}{c}200 / 320 \\
(62.5)\end{array}$ & $\begin{array}{c}202 / 284 \\
(71.1)\end{array}$ & $\begin{array}{c}124 / 319 \\
(38.9)\end{array}$ & $\begin{array}{c}194 / 262 \\
(74.0)\end{array}$ \\
\hline
\end{tabular}

PASI90/100, 90.100\% improvement in PASI score, IGA0/1=minimal or cleared(0) psoriasis, ${ }^{a}$ Data not collected at wk52, ${ }^{\mathrm{b}} \mathrm{Pts}$ with baseline PSSD scores $>0$, ${ }^{\mathrm{c}} \mathrm{Pts}$ with baseline DLQI scores>1

Conclusions: Efficacy among GUS patients was maintained through 2 years of continuous treatment. Efficacy among ADA $\rightarrow$ GUS patients improved from wks52-100. GUS was well-tolerated, with a similar safety profile as previously reported.

Disclosure of Interest: C. Griffiths Grant/research support from: Janssen Research and Development, LLC, K. Papp Grant/research support from: Janssen Research and Development, LLC, A. Kimball Grant/research support from: Janssen Research and Development, LLC, B. Randazzo Employee of: Janssen Research and Development, LLC, Y. Wasfi Employee of: Janssen Research and Development, LLC, S. Li Employee of: Janssen Research and Development, LLC, Y.-K. Shen Employee of: Janssen Research and Development, LLC, A. Blauvelt Grant/research support from: Janssen Research and Development, LLC DOI: 10.1136/annrheumdis-2018-eular.5825

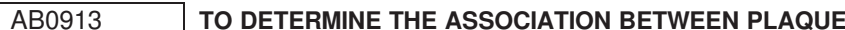 AND NON PLAQUE PSORIASIS WITH THEIR JOINT MANIFESTATION IN PSORIATIC ARTHRITIS PATIENT - A SINGLE CENTRE EXPERIENCE IN MALAYSIA}

C.R. $\mathrm{Ng}^{1}$, L. Selvarajah ${ }^{2}$, Y.L. Loh ${ }^{2} .{ }^{1}$ HOSPITAL SULTAN ISMAIL, JOHOR BAHRU, MALAYSIA, Johor Bahru, Malaysia; ${ }^{2}$ Internal medicine, HOSPITAL SULTAN ISMAIL, JOHOR BAHRU, MALAYSIA, Johor Bahru, Malaysia

Background: Psoriatic arthritis (PsA) which is a member of the spondyloarthritides includes spinal and peripheral joint involvement. It affects women and men equally. The clinical patterns of PsA were classified into 5 groups according to Moll and Wright.. ${ }^{1}$ Psoriasis is a common chronic inflammatory skin disease and chronic plaque psoriasis is the commonest form.

Objectives: To study the relationship between plaque and non-plaque psoriasis with their joint manifestation and to describe the demographic characteristics of PsA patients.

Methods: This was a restrospective study. The electronic medical records of all PsA patients under rheumatology clinic Hospital Sultan Ismail followed up from 1/ $1 / 2009$ to $31 / 12 / 2017$ were reviewed. Data on demography, type of skin disease, joint manifestation, past medical history, fasting serum lipid and body mass index were obtained and analysed.

Results: We identified 163 patients, 84 were male patients with male to female ratio of 1.06 . The Malays (84/163) were the majority being affected, followed by the Chinese (46/163), Indians (30/163) and others (3/163). The patients were divided into plaque psoriasis (140/163) and non-plaque psoriasis (23/163). The commonest joint involvement in the study was peripheral joint involvement (121/163), axial involvement (22/163) and both axial and peripheral joint involvement (20/
163). The peripheral joint involvement was categorised as polyarthritis $(67 / 121)$, followed by oligoarthritis (47/121), distal interphalangeal arthritis (4/121) and arthritis mutilans $(3 / 121)$. In the study, we divided the patients into plaque psoriasis [peripheral joint involvement (102/140); axial involvement (16/140); both (18/ $140)$ ] and non-plaque psoriasis [peripheral joint involvement (15/23); axial involve ment $(6 / 23)$; both (2/23)] and analysed the results by using the SPSS logistic regression. It showed no significant association between type of skin psoriasis with its joint manifestation. ( $p>0.05)$.

Amongst the 163 patients, 68/163 (42\%) had hypertension, 50/163 (31\%) had diabetes mellitus, $32 / 163$ (20\%) had hypercholesterolemia, 12/163 have ischaemic heart disease, 1 patient had congestive heart disease, 3 had breast cancer, 1 had hepatocellular carcinoma and 2 have chronic kidney disease and cerebral vascular disease respectively.

The fasting serum lipid (FSL) was taken for 140 of them (23 patients no data available) and it was noted in 64/140 (without background history of hypercholesterolemia was noted to have $\mathrm{FSL} \geq 5.18 \mathrm{mmol} / \mathrm{L}$ ). $37 / 64$ have borderline high total cholesterol $(5.18 \mathrm{mmol} / \mathrm{L}-<6.2 \mathrm{mmol} / \mathrm{L})$ and $27 / 64$ have high total cholestero ( $\geq 6.2 \mathrm{mmol} / \mathrm{L}$ ) according to ATP iii cholesterol classification.. ${ }^{2} 43 \%(61 / 142$ patients) had body mass index in the overweight group, $29 \%$ (41/142 patients) in the obese group and $25 \%$ (36/142 patients) in normal group according to WHO classification. $^{3}$

Conclusions: There was no association between types of skin psoriasis with their joint manifestation. There was a significant number of patients who had deranged fasting serum lipid and majority of them have BMI in the overweight and obese group.

\section{REFERENCES:}

[1] Psoriatic arthritis. Wright V, Moll JM. Bull Rheum Dis. 1971;21(5):627.

[2] ATP iii report on high blood cholesterol

[3] WHO Classification of Body Mass Index, 2004

Disclosure of Interest: None declared

DOI: 10.1136/annrheumdis-2018-eular.6493

\section{AB0914 COMPARISON OF 25-HYDROXYVITAMIN D3 SERUM LEVELS IN PATIENTS WITH PSORIATIC ARTHRITIS WITH OR WITHOUT PSORIASIS SKIN INVOLVEMENT}

C. Pijoan-Moratalla, J.R. Quiñones-Torres, M. Vázquez-Díaz. Rheumatology, HOSPITAL RAMÓN Y CAJAL, MADRID, Madrid, Spain

Objectives: To determine 25-hydroxyvitamin D3 (25OH-D3) serum levels in patients with psoriatic arthritis (PA) and to assess differences according to the presence or absence of psoriasis skin involvement. To evaluate the response to vitamin D oral supplements in case of deficiency in both groups.

Methods: We conducted an observational retrospective study including patients with diagnosis of PA according to the CASPAR classification criteria who had at least one serum determination of $25 \mathrm{OH}-\mathrm{D} 3$ in the last 36 months. Clinical and epidemiological data were collected, including arthritis distribution, age of diagnosis, presence of psoriasis skin involvement, treatment received and serum $250 \mathrm{H}-\mathrm{D} 3$ levels at baseline and within the subsequent 3 months if treatment with oral supplements had been initiated. Patients already receiving oral vitamin D supplements at baseline were excluded.

Results: Sixty patients met the inclusion criteria and were analysed. 42 were female $(70 \%)$, with a mean age of 47.6 years (range: $30-82$ ). Psoriasis skin involvement was present in 40 patients and preceded onset of arthritis in $80 \%$ of them ( $20 \%$ with psoriatic nail dystrophy). Regarding $25 \mathrm{OH}-\mathrm{D} 3$ levels, mean value was $17.99 \pm 13.23 \mathrm{ng} / \mathrm{dL}$. In the global analysis, 7 patients $(11.6 \%)$ had levels between $0-10 \mathrm{ng} / \mathrm{dL}, 22$ patients (36.6\%) between $10-20 \mathrm{ng} / \mathrm{dL}, 23$ patients (38.3\%) between $20-30 \mathrm{ng} / \mathrm{dL}, 6$ patients (10\%) between $30-40 \mathrm{ng} / \mathrm{dL}$ and 2 patients had $\geq 40 \mathrm{ng} / \mathrm{dL}$. In our sample, $58.53 \%$ of patients with psoriasis skin involvement had $25 \mathrm{OH}-\mathrm{D} 3$ levels higher than $20 \mathrm{ng} / \mathrm{dL}$, in contrast to the group without skin involvement, who reached sufficiency levels only in $37.5 \%$ of the cases. In the comparative analysis, patients with psoriasis skin involvement had a mean $25 \mathrm{OH}-\mathrm{D} 3$ serum level of $20.88 \mathrm{ng} / \mathrm{dL}$ whereas patients without skin involvement had lower levels (mean value $19.42 \mathrm{ng} / \mathrm{dL}$ ). Similarly, patients with skin psoriasis had more frequently $250 \mathrm{H}-\mathrm{D} 3$ levels between $20-30 \mathrm{ng} / \mathrm{dL}$ (insufficiency) compared to those without this manifestation, who presented lower levels (44\% vs $16 \%$ ) but without statistically significant difference. Results are shown in Figure 1. Finally, all patients presenting $250 \mathrm{H}-\mathrm{D} 3$ deficiency at baseline $(<20 \mathrm{ng} /$ $\mathrm{dL}$ ) were treated with oral supplements (calcifediol $0.266 \mathrm{mg}$ every two weeks). Of them, 23 patients had a second determination of $250 \mathrm{H}-\mathrm{D} 3$ within the subsequent 3 months, with only 13 patients reaching sufficient levels $(56 \%)$, whereas the rest did not respond to the dose administered. No statistically significant differences were found in the response depending on the presence or absence of cutaneous psoriasis. 